\title{
DIVERSIDADE DE GÊNERO E SEXUAL E FORMAÇÃO DOCENTE: O PIBID COMO LUGAR DE TRAVESSIA E AVENTURA
}

Marcos Lopes de Souza Anderson Ferrari(*)

PRA COMEÇO DE CONVERSA...

Há algum tempo, a formação de professoras/es tem sido um tema em voga nos fóruns de educação, nos congressos de pesquisadoras/es e no próprio movimento sindical docente, inclusive tem sido apontada como umas das questões que interfere diretamente na prática pedagógica. Corriqueiramente, o corpo docente tem requerido o direito à formação permanente e apontado a ausência desses momentos formativos como um dos motivos para o insucesso escolar. Com isso os espaços de formação docente têm sido uma reivindicação muito grande, sobretudo, por parte das/os educadoras/es.

Reconhecendo a relevância da formação docente, mas não a entendendo como a saída para as questões educacionais, nos debruçamos em pensá-la e debatê-la em uma perspectiva que a entende como um lugar plural, incerto, instável, conflituoso e, poucas vezes, inabalável. Portanto, nos distanciamos de olhares outros que a têm visto como um espaço seguro, de aprendizagem de novas técnicas ou de metodologias, de acúmulo de conhecimentos e de respostas seguras e definitivas para os problemas da prática para nos aproximarmos, no encontro com Larrosa (2014), de uma compreensão da formação enquanto espaço provocativo, de desequilíbrios, de desapego das certezas e verdades que trazemos conosco, que tenha abertura, gere estranhamentos, mexa com o que somos e sabemos, estimule a surpresa, o desconhecido e reivindique a experiência, esta última podendo ser vista como o que nos acontece, nos transforma e nos singulariza.

Dentre os aspectos que perpassam esse processo de formação docente somos capturados pelas questões de gênero e de sexualidade, as quais ainda têm tido um lugar marginal nos currículos dos cursos de formação de professoras/es. Baseando-se em outras investigações (CASTRO, 2013;

\footnotetext{
${ }^{(*)}$ Marcos Lopes de Souza. Professor Adjunto da UESB do departamento de Ciências Biológicas, professor permanente do programa de Pós-graduação em Educação Científica e formação de professores. E-mail: markuslopessouza@gmail.com

Anderson Ferrari. Professor Adjunto da Faculdade de Educação e professor permanente do programa de Pós graduação em Educação, ambos ligados a Universidade Federal de Juiz de Fora. E-mail: aferrari13@globo.com
} 
FERREIRA; BARZANO, 2013) e em nossas vivências percebemos que ainda são limitados os debates sobre diversidade de gênero e sexual no ensino de graduação, restringindo-se, em geral, aos componentes curriculares optativos (esses, muitas vezes, rejeitados), em alguns casos às disciplinas obrigatórias ou então, aos projetos de pesquisa e de extensão desenvolvidos por docentes que trabalham com a temática. Destaca-se que, muitas vezes, o trabalho com as questões de gênero e sexualidade nos cursos de formação docente surgem de interesses individuais de algumas/alguns docentes e, poucas vezes com o apoio das(os) colegas. Portanto, assumir essas discussões tem significado colocar-se à prova, correr riscos, disputar espaços, sofrer retaliações, enfrentar os bombardeios, muitas vezes intensos, mas também se lambuzar com os encontros e desencontros entre os sujeitos envolvidos.

Sabendo das inúmeras barreiras e desafios que nos deparamos ao trazer à tona as questões de diversidade de gênero e sexual nos aventuramos em apostar no Programa Institucional de Bolsa de Iniciação à Docência (PIBID) como um espaço pulsante para desenvolvermos essas discussões na formação docente. Criado em 2007 pelo governo federal, o PIBID é uma das políticas públicas que tem o propósito de estimular e valorizar a profissão docente e contribuir com a formação de professoras/professores. Uma das intencionalidades é promover a vivência das(os) licenciandas(os) no cotidiano das escolas da rede pública de educação por meio de ações contínuas e, ao mesmo tempo, estreitar os laços entre docentes das escolas e as instituições de ensino superior (BRASIL, 2010).

Nesse programa são oferecidas bolsas às(aos) estudantes dos cursos de licenciatura, à(ao) docente universitária(o) que coordena cada projeto, à(ao) coordenadora/coordenador institucional e também às(aos) docentes de escolas públicas vinculadas(os) ao projeto. Para participarem desse programa, as instituições de ensino superior (federais, estaduais e privadas) encaminham os seus projetos conforme os editais da Coordenação de Aperfeiçoamento de Pessoal de Nível Superior (CAPES) para concorrerem às bolsas.

Diante da relevância do PIBID no contexto mais recente, propusemos realizar uma pesquisa a fim de analisar as potencialidades e limitações de uma abordagem das discussões sobre diversidade de gênero e sexual em um espaço formativo envolvendo licenciandas(os) e professoras(es) da educação básica tendo como pressuposto a desnaturalização e a desestabilização das visões normatizadoras e normalizadoras dos gêneros e das sexualidades.

Tomando o PIBID como lugar de diálogo sobre gênero e diversidade sexual, investimos em contatar as coordenações dos projetos do PIBID existentes na Universidade Federal de Juiz de Fora (UFJF) em Juiz de Fora-MG para identificar o interesse em dialogar sobre essas questões. Obtivemos um retorno de algumas delas, destacando-se, o PIBID vinculado à educação infantil que 
desenvolve ações em duas creches do município. Conforme a Lei de Diretrizes e Bases da Educação Nacional, a educação infantil é oferecida em creches para crianças de até 3 anos de idade e em pré-escolas para crianças de 4 a 5 anos (BRASIL, 1996).

Dialogamos com a coordenadora do PIBID creche e ela ficou motivada para que pudéssemos construir momentos de debate com o grupo sobre as questões envolvendo gênero e diversidade sexual. Além da coordenadora, participam do projeto três educadoras da creche e dez estudantes do curso de Pedagogia. Foi realizado um primeiro encontro, no qual se apresentou o propósito da pesquisa, nosso desejo em construir esse espaço de discussão e também se mencionou que o projeto de pesquisa tinha sido aprovado pelo Comitê de Ética em Pesquisa da Universidade Estadual do Sudoeste da Bahia (UESB). Todas as participantes do trabalho foram esclarecidas sobre os propósitos da investigação e assinaram um termo de consentimento de sua participação no estudo. Depois desse primeiro momento, passamos a desenvolver o estudo quinzenalmente durante as reuniões do grupo.

Neste artigo optamos por compartilhar e também debater algumas das cenas ocorridas na primeira ação com essa turma do PIBID. Nesse dia elaboramos algumas questões gerais referentes aos aspectos como: situações relacionadas à sexualidade vivenciadas na escola; formação e o trabalho com as questões de gênero e de sexualidade; questões de gênero e sexualidade consideradas intrigantes e provocativas, além do papel da escola no debate sobre gênero e sexualidade. As participantes perguntavam entre si e dialogavam conforme seus pontos de vista. $\mathrm{O}$ intuito era promover um ambiente que incitasse debates escapando de uma ação prescritiva ou resolutiva, inclusive outras questões não relacionadas aos questionamentos surgiram ao longo do debate.

São essas cenas que iremos tomar como ponto de partida para as problematizações, sob a perspectiva teórico-metodológica pós estruturalista que nos convida a pensar a construção discursiva dos sujeitos. Adotar a perspectiva pós-estruturalista, sob inspiração dos estudos foucaultianos, é trabalhar com a noção de problematização como um caminho para a frente, vinculado a história do pensamento e que não se propõe a oferecer soluções, proporcionando a oportunidade de ampliar o debate sobre pesquisa no campo educacional, buscando a problematização como possibilidade de fazer pesquisa em educação. Problematizar está inscrita na história do pensamento para questionar porque pensamos o que pensamos? Como vamos construindo nossas formas de pensar e agir? Como somos resultados desses saberes e poderes?

Destacamos alguns episódios do primeiro encontro que mais nos suscitaram pensar a escola e essa relação com gênero e sexualidade. Inicialmente apresentaremos as três cenas selecionadas e, posteriormente, nossas reflexões construídas com base nesses relatos. 


\section{CENAS ESCOLARES PRODUZIDAS PELAS PARTICIPANTES DO PIBID}

\section{CENA 1}

Isabela - Eu tava no estágio não obrigatório. Não sei o que deu em mim que eu quis trabalhar. Eu tava no primeiro período totalmente sem experiência de nada. E eu cheguei na creche. No primeiro dia que eu fui lá a dona da escola falou assim: Não, pode vim, você estuda na Federal, pode vim. Eu fui e no primeiro dia, a menininha baixou as calças pro um monte de menininho que tava na sala e ficou sem calcinha. E tipo assim eu fiquei desesperada. Eu falei: Meu Deus o que que eu faço? Aí na mesma hora a dona da escola veio e suspendeu a menina. Gritou com ela, colocou ela no canto. E até hoje, tipo assim se acontecesse comigo de novo eu não sei o que eu faria.

\section{CENA 2}

Luana - A gente vê um despreparo muito grande. Se você entrar em uma escola de educação infantil você vê. O exemplo claro é na unidade que eu coordeno hoje eu tenho vinte funcionários e um homem dentro da unidade. Então assim são questões que vão sendo estabelecidas até no módulo que nós tivemos lá no Centro de Formação de Professores lá na Secretaria de Educação de Juiz de Fora, uma vez nós entramos nessa discussão. Desde quando eu entrei. Eu entrei em 2005. Eu entrei como educadora. Aí a gente ouve falar que o homem não pode olhar o repouso, que tem o repouso das crianças, o homem não pode dar banho e o homem não pode levar as crianças ao banheiro. Aí a gente vai fazendo essas questões muito automaticamente. E eu era educadora na época e depois que eu passei para coordenação eu tinha, anterior a este homem que eu tenho hoje, eu tinha uma pessoa que eu tinha muito confiança nele. Eu tinha muito confiança no trabalho dele. Ele cuidava do repouso quando eu precisava, acudia uma criança no banheiro. Aí você vê e se questiona: Onde se estipulou que o homem não pode olhar o repouso de uma criança na creche, que o homem não pode dar um banho, se o homem pode ser pai? Quer dizer ele pode dar muito melhor que uma mulher e o que a mulher faz que o homem não pode fazer? A gente associa muitas vezes o homem a cuidar dessa criança a querer abusar sexualmente. E por que não a mulher abusar sexualmente de uma criança? E quando levantou essa discussão e, eu não sei de onde veio, já se ouviu caso, dentro da comunidade de que a própria mulher abusou com a mão, com o uso da mão, de uma criança. Então são questões que vão perpassando e, muitas vezes, a gente não questiona.

\section{CENA 3}

Adriana - Eu acho também que a creche interfere nessa relação da sexualidade e família. Uma vez teve os cantinhos. Tinha o cantinho da beleza. Aí no cantinho da beleza tinha batom, esmalte. Você lembra, Luana, dessa parte? E aí as meninas ficaram muito preocupadas. A gente não vai deixar os meninos usar o cantinho, né? Aí a coordenadora disse que não. A gente vai fazer uma reunião com as famílias e vamos dizer que estamos fazendo esse projeto dos cantinhos. Se uma criança, às vezes, passar um esmalte, vamos explicar para os pais.

Luana - Esses são cantinhos temáticos. A gente tem na creche cantinho da higiene e beleza, cantinho da fantasia, cantinho do carrinho, cantinho da boneca, da construção. E nesse trabalho você dá liberdade de escolha pra criança. O educador vai montar os cantinhos na sala 
dele e as crianças vão brincar onde elas querem. Então esse cantinho que a Adriana tá citando é um cantinho que deu muita polêmica e ainda dá até hoje. Vira e mexe elas falam, mas Luana o que eu faço? Porque no cantinho de beleza elas arrumam o cabelo e tem vários meninos que querem passar o esmalte vermelho. Eu tenho um lá que ele é muito vaidoso, ele adora batom, ele fica alucinado. E assim as meninas tinham muito essa dúvida. E teve algumas creches que teve problema mesmo com a família: Ah, meu filho vai virar viado se ele passar esmalte, se ele passar batom. E você mostrar isso pra criança? A criança não tem essa maldade. É o adulto que coloca isso que ela não pode passar sombra. (...) Será que ele tem uma tendência a ser homossexual? Aí eu disse: o que é ter uma tendência? O que você entende por ter uma tendência? Por que não pensar que ele está representando a mãe? Que ele tem até uma idolatria pela mãe, pela figura materna, pela mulher. Às vezes, a gente se realiza no faz de conta. Isso é da criança. Só que o adulto, muitas vezes, não olha dessa forma. Você vê que não é só da cabeça dela: Existe isso? Vamos pesquisar se existe uma tendência a ser homossexual? Existe algum estudo com base nisso? Se tem uma pré-disposição a algo? Se se torna? Então a gente começou a dialogar. Hoje elas lidam muito melhor com essas situações. As crianças vestem o vestido e, assim, sucessivamente.

\section{AS POTENCIALIDADES DAS ESCOLAS}

Desespero, despreparo, surpresa e intervenção são palavras que traduzem as três cenas construídas acima e que nos convida a pensar as potencialidades presentes na escola. Em todas as três cenas, é no encontro com a sala de aula que as questões problematizadoras surgem, conduzindo ao encontro com a formação e, mais do que isso, servindo para colocar sob suspeita a formação. Minimamente podemos pensar que o contexto escolar nos possibilita entrar no jogo que se estabelece entre o que sabemos, como construímos o que sabemos, como agimos, os sentidos que damos ao saber e agir e a constituição das subjetividades, tanto as nossas como professores que assumimos o lugar do saber e do agir e dos alunos e alunas que somos capazes de construir a partir desses jogos de saber e poder.

Podemos pensar que grande parte da formação docente ocorre no espaço das escolas, no convívio com o cotidiano escolar. Nas três cenas isso aparece com toda sua potencialidade. No primeiro caso, a escola parece chamar, de maneira que a estudante não sabe porque foi para escola, mas reconhece o seu poder de atração advindo do entendimento que é na prática que se aprende. Diz ela: "Eu tava no estágio não obrigatório. Não sei o que deu em mim que eu quis trabalhar. Eu tava no primeiro período totalmente sem experiência de nada. E eu cheguei na creche”. No entanto, não é fato de estar no primeiro ou último ano de formação que parece fazer a diferença quando a questão diz respeito às problemáticas que estão na escola. O que as três cenas parecem denunciar é que a formação docente nunca dará conta da riqueza que é o dia a dia das escolas, em que o imprevisível está sempre presente. É neste cotidiano que entramos em contato com algo que nos exige uma ação, que nem sempre foi vivenciado na formação acadêmica e que nos coloca diante das nossas construções. Ao mesmo tempo, estar nas escolas vai formando um saber, 
fornecendo um lugar de sujeito como aquele que sabe porque vive e que permite construir um conhecimento e, muitas vezes, uma forma de agir como o ideal e o correto, estabelecendo uma relação de avaliação do próprio trabalho e do trabalho do outro. Não é à toa que na segunda cena, é assumido o lugar da educadora que se torna coordenadora e que, portanto fala: "A gente vê um despreparo muito grande. Se você entrar em uma escola de educação infantil você vê. (...) Desde quando eu entrei. Eu entrei em 2005. Eu entrei como educadora”.

É nas escolas que vamos constituindo esses lugares de sujeito (FOUCAULT, 1988, 2006) e vamos assumindo essas relações de poder. O espaço de discussão possibilitado por essas reuniões do PIBID, espaços em que são construídas essas cenas são, em certa medida, espaços em que estão construindo a história de como cada um se constituiu e estão se constituindo em sujeitos de verdade. Por isso, essas cenas vêm à tona, ou seja, elas servem para dizer como nos assujeitamos às verdades do nosso tempo, de maneira que somos capazes de enxergar determinadas situações, construir determinadas cenas e não outras. Somos uma sociedade herdeira de um tempo - a Modernidade que nos constitui e que segundo Foucault (1988), foi capaz de nos ensinar a construir discursos sobre nós mesmos, de maneira que não cansamos de buscar discursos verdadeiros que nos formam.

Desta forma, a fala que inicia a terceira cena caminha na contramão do que comumente escutamos quando o assunto é as sexualidades nas escolas. Diz a professora: "Eu acho também que a creche interfere nessa relação da sexualidade e família”. Comumente, o inverso é tido como problemático, ou seja, quando a interferência no trabalho das escolas vem das famílias, quase sempre reclamando de uma ação nos sujeitos que não é entendida como ideal. De alguma forma, a escola age, reage e perturba, por isso, nem sempre o silêncio ou o recuo tomam a frente, como algumas vezes escutamos de outras vivências escolares. Tanto um quanto outro tipo de intervenção, seja das escolas nas famílias ou o inverso, pode ser problematizado a partir daquilo que Foucault (1992) chama atenção e que diz das possibilidades de discursos e que nos incita a questionar que as coisas ditas são sempre históricas, o que significa dizer que elas funcionam sempre em práticas muito concretas. É a prática que forma os objetos de que fala. Por isso as escolas adquirem tanta força, poder e importância na formação. É lá no "chão das escolas" que as nossas verdades, os discursos que nos constituem aparecem, sejam aqueles que apreendemos na formação inicial ou aqueles que nos constituíram ao longo de toda vida.

As cenas são associadas, antes de tudo, a diferentes concepções de sujeito: professoras, coordenadoras, meninos, meninas, professores homens de creche, pais, enfim, sujeitos diferentes resultados dos variados investimentos de poder saber. Assim, podemos pensar as escolas como resultado dessas associações de inúmeras práticas sociais, que estão construindo sujeitos, saberes, 
corpos, modos de existência não somente de pessoas como de instituições, como por exemplo, a própria escola, família e a secretaria de Educação.

\section{RELAÇÕES DE GÊNERO, QUESTÕES DAS SEXUALIDADES E O PIBID}

Se no encontro com as escolas que a formação se potencializa no sentido de estabelecer que saberes nos constituem, nos imobilizam, nos faltam, é também a partir deste encontro com as escolas que surgem as necessidades de mais estudos e ações práticas. As sexualidades nas escolas surgem em meio a outros fenômenos, tais como as relações do que assistimos com um conjunto de conhecimentos diversos, desde aspectos biológicos a comportamentos individuais, sociais e corporais que colocamos em circulação neste ato de ver e narrar o que vemos; o conjunto de regras e normas da sociedade e das escolas que vão definindo o que pode e o que não pode para homens e mulheres; as relações com outras instituições como família e igreja; a maneira como os indivíduos são levados a dar sentido e valor as suas condutas e a dos outros, sem esquecer dos prazeres, sentimentos e sensações envolvidos nestes processos. Isso tudo está presente nas escolas e dizem das relações de gênero e de sexualidades que vamos construindo.

As relações de gênero não são simples categorias analíticas. Como nos lembram Scott (1991) e Week (2007), além das feministas, o gênero diz de uma relação de poder, de maneira que homens e mulheres são produtos de poder que definem o que é necessário, desejável e controlável para homens e mulheres de forma relacional. Essas relações são construídas no social e a escola fazendo parte deste contexto também é o lugar em que isso ocorre numa ação que é dela, mas também é de uns sobre outros e de nós mesmos sobre nossas condutas. Ao entrar nas escolas levamos para dentro destes contextos nossas concepções de homem e mulher e vamos dando lugares a eles e elas. Mas a presença de meninos e meninas com suas sexualidades, prazeres, condutas, corpos, conhecimentos também agem sobre nós professores. O que ocorre quando nos deparamos com o "inesperado"? Porque algo se traduz como "inesperado" no contexto escolar? As três cenas escolhidas para este artigo diz deste "inesperado".

Na primeira delas uma jovem estudante diz do encontro com este "inesperado" logo no seu primeiro dia de estágio: "Eu fui e no primeiro dia, a menininha baixou as calças pro um monte de menininho que tava na sala e ficou sem calcinha. E tipo assim eu fiquei desesperada. Eu falei: Meu Deus o que que eu faço". A ação de uma menina na creche que causa um "desespero" na estudante e que a coloca diante do sentimento de incapacidade de ação, talvez porque desde o início tenha entendido esta relação com o corpo como algo que deveria ser reprimido, vigiado e, portanto, exigia uma ação de controle por parte dela. Essa preocupação em regular a sexualidade das crianças já 
vem, conforme Foucault (1988) desde o século XVIII e XIX em que se buscou corrigir as crianças ditas precoces e combater a masturbação mobilizando pedagogos, médicos e familiares.

Com base na narrativa da graduanda da primeira cena vemos que houve uma ação controladora e repressiva da diretora que preferiu censurar a menina advertindo-a e castigando-a, o que para alguns/algumas poderia ser uma orientação em como lidar em situações como essa, pois seria a voz de alguém com maior tempo na docência e de que está em um lugar de direcionamentos. Por outro lado, a jovem não tomou esse posicionamento da diretora como "a" resposta, pois mesmo tendo sido provocada com a ação da garotinha, ela ainda encontrava-se insegura, sem respostas e caso vivenciasse outra situação semelhante ainda não saberia como agir. Essa incerteza em como agir pode parecer, a princípio, uma incapacidade de atuar ou uma deficiência na formação, entretanto, vemos como uma brecha, uma possibilidade de problematizar e de desestabilizar as normas que produzem as formas de pensar e de agir frente às questões de gênero e de sexualidade, em outras palavras, é uma forma de não encerrar o assunto, mas mantê-lo aceso.

A cena dois também nos diz do "inesperado" que só adquire significado a partir daquilo que estabelecemos como lugares de homens e mulheres na escola. É ainda rara a presença de professores homens nas creches, entendidas como um prolongamento da atividade feminina, da casa para escola, muito semelhante ao trabalho materno. Falando de um despreparo da escola em lidar com este inesperado que embaralha as questões de gênero com sexualidades, a coordenadora exemplifica: "O exemplo claro é na unidade que eu coordeno hoje eu tenho vinte funcionários e um homem dentro da unidade”. E continua: "Aí a gente ouve falar que o homem não pode olhar o repouso, que tem o repouso das crianças, o homem não pode dar banho e o homem não pode levar as crianças ao banheiro. Aí a gente vai fazendo essas questões muito automaticamente”.

Essa proibição do homem na realização de algumas ações na creche no episódio relatado por uma das educadoras está pautada em um pensamento de que o homem é um perigo em potencial para essas crianças no que diz respeito à possibilidade de violentá-las sexualmente. Mesmo que ele tenha a formação no magistério, há aí um receio muito grande, partindo não só de quem está nas creches, mas pelos próprios gestores municipais, conforme mencionado pela participante, dessa maneira, muitas creches preferem não correr o risco. Ao analisar a carreira do magistério, percebemos que a instituição escolar se origina em uma matriz masculina e religiosa, já que foram os homens e, em sua maioria, católicos, os primeiros educadores das escolas brasileiras, contudo uma entrada maior das mulheres no magistério vai ocorrendo ao final do século XIX e se intensifica durante o século XX, permanecendo nos dias atuais. Com isso há uma modificação na forma de pensar a docência, passando a ser vista como uma extensão da casa e da maternidade e, assim, o 
cuidado e o amor tornam-se elementos importantes na profissão, tendo respaldo, inclusive nos estudos da Psicologia e com isso busca-se ajustar a carreira docente enquanto um ofício feminino (LOURO, 1997). De outra maneira, entendemos que a feminização do magistério não foi e nem continua sendo um processo tranquilo e afinado, mas contraditório e marcado por inúmeros dilemas, especialmente quando se trata da educação das crianças, pois envolve questões que perpassam pela desvalorização da carreira, pelas precárias condições de trabalho, os salários irrisórios, a reiteração da docência como vocação e entre outras coisas (VIANNA, 2002). Além do que, ao marcar o magistério como profissão da mulher dificultam-se os trânsitos e os fluxos de gênero tanto para os homens quanto para as próprias mulheres.

E para acirrar essa discussão da docência enquanto uma carreira das mulheres, percebemos que o homem se torna uma ameaça quando se coloca em pauta a violência sexual, nesse caso relacionada à pedofilia, o que não é visto da mesma forma quando se refere à mulher. Aqui há um resgate na compreensão essencialista e naturalizante dos binarimos de gênero e de sexualidade ao pressupor que o homem seja naturalmente agressivo e traga intrinsicamente um desejo sexual incontrolável e que a mulher, contrariamente, jamais seja violentadora. Em investigações mais recentes como a de Monteiro e Altmann (2014) realizada com professores da educação infantil do município de Campinas-SP foi também percebido o estranhamento em relação à presença de homens como educadores nas creches e dentre as questões que promovem essa rejeição está o fato de que eles poderiam, em alguma circunstância, abusar dessas crianças, especialmente, as meninas. Os momentos do banho e do uso do sanitário são os mais difíceis, por isso, para evitar essas suspeitas um dos entrevistados procura desenvolver a autonomia nas crianças para que elas façam essas atividades sozinhas. Em outro caso, evita-se a atribuição de turmas de crianças de 0 a 3 anos aos professores.

Entendemos que nessa discussão sobre as relações de gênero e a educação infantil as ideias normativas e fixas das masculinidades e feminilidades ainda são afirmadas continuamente dificultando a fluidez e a construção de tantas outras possibilidades de gênero. Todavia, a professora que trouxe a cena dois se inquieta diante desse olhar que se construiu em relação ao homem como sendo, incondicionalmente, um agressor e ela, inclusive, perturba e confronta essas questões no espaço em que atua como diretora quando encoraja um de seus funcionários a cuidar das crianças.

Construir essas cenas no espaço de discussão do PIBID nos coloca uma questão importante para pensar a formação docente, relações de gênero e sexualidades: o que acontece com as relações de gênero e com as sexualidades quando professores e professoras começam a discutí-las a partir do 
que encontram na escola? Modificam-se as percepções de gênero e sexualidades a partir desta discussão? Modificam-se as professoras diante deste "inesperado" das escolas? Podemos pensar que a cultura presente nas escolas nos leva a buscar respostas estáveis e imediatas para estas questões, algo que seja esperado pela comunidade escolar e pelas famílias, ao invés de nos envolvermos no diálogo franco em que possamos pensar as nossas formações não somente como docentes, mas como sujeitos de uma sexualidade, de uma sociedade que nos incita a falar sobre os nossos desejos, prazeres e ações. Na escola o que parece dominar é o fato em si, muito mais do que um incentivo a compreensão de questões íntimas que estão envolvidas nestas construções. Assim, vamos impedindo o exercício de certa curiosidade que envolve o corpo, as sensações. Trabalhar com educação é trabalhar com curiosidade. Como lembra Britzman (2007), não há educação sem curiosidade. A curiosidade é capaz de levar meninos e meninas, professores e professoras a direções que podem ser surpreendentes, capazes de romper com o quê quase sempre domina as discussões de gênero e sexualidade, ou seja, a busca por respostas e atitudes consideradas "certas" ou "erradas".

Com a curiosidade acrescentamos mais um aspecto ao "inesperado". Curiosidade e o inesperado também estão presentes na cena 3: "Porque no cantinho de beleza elas arrumam o cabelo e tem vários meninos que querem passar o esmalte vermelho. Eu tenho um lá que ele é muito vaidoso, ele adora batom, ele fica alucinado. E assim as meninas tinham muito essa dúvida. E teve algumas creches que teve problema mesmo com a família: Ah, meu filho vai virar viado se e ele passar esmalte, se ele passar batom".

Ao produzir os chamados cantinhos e abrir espaços para a vivência com menor controle e regulação onde as crianças admirem, provem e experimentem aquilo que elas desejam e se identificam, a escola está provocando as famílias, fazendo-as sair do seu lugar cômodo, desafiando os processos de naturalização dos gêneros e das sexualidades e distanciando-se, mesmo que pontualmente, de um espaço educativo que, continuamente, quer disciplinar os corpos, os gêneros e sexualidades. Mesmo que houvesse reclamações por parte das famílias, a escola assumiu esse enfrentamento, inclusive a professora relatou indagações que ocorreram em outra creche em que também se trabalhou com os cantinhos.

Outra questão instigante é sobre a inquietude e a dúvida que perseguem as educadoras da creche quando os meninos desejam explorar os cantinhos que transgridem as marcas normatizadoras da masculinidade. A primeira iniciativa das educadoras é querer proibir os meninos de usar maquiagem ou algum vestido, todavia, a coordenadora assume os riscos e sugere deixar os meninos desfrutarem dos cantinhos e, mesmo quando essas vivências já se tornam mais comum, vez ou outra, algumas educadoras ainda se veem perdidas, possivelmente porque as nossas 
aprendizagens das normas dos gêneros e sexualidades foram tão arraigadas que não conseguimos lidar com esses atravessamentos. É interessante também perceber como esse incômodo parte das educadoras e, poucas vezes, as crianças inclusive as que promovem essas transgressões se sentem receosos ou constrangidos. Em um estudo feito por Silva e Luz (2010) com professoras da educação infantil de uma instituição pública em Belo Horizonte-MG, entendeu-se que muitas delas vivem em situações de conflito e contraditoriedade, pois embora reconheçam as discussões sobre diferenças e as relações de gênero e sexualidade ainda têm dificuldades em questionar os modelos padronizados e, de alguma forma, buscam por meio de repetidos esforços enquadrar as crianças nesses lugares polarizados. Por exemplo, no caso dos meninos há uma preocupação menor em relação ao cuidado e à demonstração de afeto por parte das professoras e uma restrição para os garotos em brincar com bonecas e de casinha.

Mesmo com esses processos de regulação, há escapes e fugas e, de alguma forma, as crianças reagem a esses processos normativos e normalizadores como foi o caso apontado na cena três em que os meninos rompiam esses enquadramentos dos corpos, gênero e sexualidade. Uma situação próxima foi trazida no artigo de Vianna e Finco (2009) em que um garoto gostava de se vestir de noiva quando ia para a brinquedoteca da escola e que pedia a professora para colocar o vestido nele e o quanto isso a desestruturou, pois para ela o vestido é para a mulher e que, com isso, ele estaria "ultrapassando" os limites fixos das relações de gênero, porém, mesmo negando ao garoto o vestido de noiva, ele continuou desejando outros. Esses meninos questionadores e que ousam cruzar as fronteiras de gênero produzem ensinamentos, especialmente para as educadoras, ao desafiarem as normas de gênero e de sexualidade e resistirem mesmo quando são continuamente insultados, ridicularizados, vistos como excêntricos e colocados à margem.

Nessa vigilância da masculinidade o que, talvez, mais incomode muitas educadoras é a suposta "tendência homossexual" do(s) garoto(s) e aí uma busca desesperada entorno disso é feita, conforme contou a professora da cena 3: Vamos pesquisar se existe uma tendência a ser homossexual? Existe algum estudo com base nisso? Se tem uma pré-disposição a algo? Se se torna? Então a gente começou a dialogar.

Essa busca incessante por uma causa ou tendência da homossexualidade pauta-se em um pensamento de que a heterossexualidade é natural e as "outras" expressões da sexualidade são desviantes e, portanto, deve-se buscar a possível "causa" para que as pessoas não sigam "o caminho esperado" que seria o da heterossexualidade. Por isso, muitas professoras demonstram pânico quando se deparam com situações como as descritas na cena três e preocupam-se com o fato de que estariam "incentivando" ou sendo permissivas com um desejo visto como anormal. Entretanto, elas 
desconsideram a heterossexualidade como uma produção impositiva e contínua sobre os corpos e de que a existência da heterossexualidade só ocorre por conta da homossexualidade, ou seja, são interdependentes, sendo que ao nomear a homossexualidade como antinatural e ilegítima, a heterossexualidade mantém o seu lugar de supostamente coerente e superior (MISKOLCI, 2009). É provável que esse seja um dos grandes desafios também para a escola, colocar a heterossexualidade sob suspeita.

\section{E A ESCOLA E O PIBID DIANTE DESTAS QUESTÕES?}

As cenas que trouxemos para compartilhar e também tecer considerações nos chamam para pensar a escola como um espaço ativo, de possibilidades, produção e também de amarras e de controle, enfim um lugar onde as coisas acontecem. Entretanto, muito do que acontece na escola ainda é pouco considerado ou problematizado nos espaços de formação docente e esse é um dos pontos que apostamos no PIBID enquanto potencializador desses acontecimentos que nos afetam. Apesar de muitas/os professoras/es esperarem que os espaços formativos lhes tragam as receitas para lidarem com as situações que as/os atinge na escola, queremos nos distanciar dessa aposta que nos é feita para arriscar em uma formação que nos cause estranheza, surpreenda, nos mobilize pensar o impensável e que nos faça adentrar um terreno desconhecido.

Pensando nessa direção, embora não saibamos onde chegaremos, nos atrai cogitar o PIBID como um espaço que se preocupe mais com as perguntas do que com as respostas, não que nos imobilize frente às situações que nos deparemos mas que não feche as possibilidades e sim que fomente as aberturas e estimule as frestas. Não é uma tarefa fácil, talvez extremamente obscura, mas potente. Entendendo dessa maneira, vemos quantas interrogações e dúvidas nos surgem a partir das cenas aqui relatadas. Devaneamos em questões como: Por que nos é estranho ver um garoto usar um esmalte vermelho, ou um batom ou mesmo um vestido? Por que produzimos o homem como um agressor sexual em potencial? Por que algumas professoras ousam contestar os regimes de verdade e se permitem transgredí-los? Não temos a pretensão de respondê-las e sim que mexam conosco, nos tire do lugar seguro e intocável e nos desestruture. Amparando-nos nas ideias de Larrosa, aventuramo-nos em ver o PIBID como esse lugar em que possamos partilhar de nossas experiências. Nas suas palavras:

A experiência é o que nos acontece, não o que acontece, mas sim o que nos acontece. Mesmo que tenha a ver com a ação, mesmo que às vezes aconteça na ação, não se faz a experiência, mas sim se sofre, não é intencional, não está do lado da ação e sim do lado da paixão. Por isso 
a experiência é atenção, escuta, abertura, disponibilidade, sensibilidade, exposição (LARROSA, 2014, p. 68).

Em se tratando de um PIBID com foco para a educação infantil nos é mais desafiador, pois as formas de regulação e de controle dos corpos, dos gêneros e das sexualidades em relação às crianças são intensas, às vezes tênues, outras escancaradas. Há também o uso de mecanismos repressivos quando essas crianças desafiam as normas e se desviam delas e, para isso, são inúmeras as coerções e correções. De repente é isso que nos anima mais para adentar nessa arena e ir para os confrontos esperando que a formação docente permaneça em movimento.

\section{REFERÊNCIAS}

BRASIL. Congresso Nacional. Lei no 9394 de 20 de dezembro de 1996. Estabelece as diretrizes e bases da educação nacional. D. O. U. de 23/12/1996.

BRASIL. Presidência da República. Decreto n ${ }^{\circ}$ 7.219, de 24 de junho de 2010. Dispõe sobre o Programa Institucional de Bolsa de Iniciação à Docência - PIBID e dá outras providências. D. O. U. de 25/06/2010.

BRITZMAN, Deborah. Curiosidade, sexualidade e currículo. In: LOURO, Guacira Lopes. O corpo educado: pedagogias da sexualidade. Belo Horizonte: Autêntica, 2007, p. 83-112.

CASTRO, R. P. Formação docente, subjetividades e experiência: problematizações a partir dos percursos, pela pesquisa e pela docência. In: FERRARI, A. (org.). A potencialidade do conceito de experiência para a educação. Juiz de Fora: Ed. UFJF, 2013, p. 139-158.

FERREIRA, T. S.; BARZANO, M. A. L. Modos de ver, sentir e questionar: a presença do gênero e da sexualidade no curso de Pedagogia. Revista da FAEEBA - Educação e Contemporaneidade, Salvador, v. 22, n. 40, pp. 247-258, 2013.

FOUCAULT, M. História da sexualidade I: a vontade de saber. Rio de Janeiro: Edições Graal, 1988.

Ética, sexualidade, política. Ditos e escritos V. Rio de Janeiro: Forense Universitária, 2006.

LARROSA, J. Tremores: escritos sobre experiência. Belo Horizonte: Autêntica Editora, 2014.

LOURO, G. L. Gênero, sexualidade e educação: uma perspectiva pós-estruturalista. Petrópolis, RJ: Vozes, 1997.

MISKOLCI, R. A teoria queer e a sociologia: o desafio de um analítica da normalização. Sociologias, Porto Alegre, ano 11, n. 21, p. 150-182, jan./jun. 2009.

MONTEIRO, M. K.; ALTMANN, H. Homens na educação infantil: olhares de suspeita e tentativas de segregação. Cadernos de Pesquisa, São Paulo, v. 44, n. 153, p. 720-741, 2014.

SCOTT, Joan W. Gênero: uma categoria útil de análise histórica. Educação \& Realidade, Porto Alegre, v. 2, n. 16, p. 522, jul/dez 1995.

SILVA, I. O.; LUZ, I. R. Meninos na educação infantil: o olhar das educadoras sobre a diversidade de gênero. Cadernos Pagu, Campinas, n. 34, p. 17-39, 2010.

VIANNA, C. P. O sexo e o gênero da docência. Cadernos Pagu, Campinas, n. 17-18, p. 81-103, 2002.

VIANNA, C.; FINCO, D. Meninas e meninos na Educação Infantil: uma questão de gênero e poder. Cadernos Pagu, Campinas, 2009, n.33, p. 265-283, 2009.

WEEKS, Jeffrey. O corpo e a sexualidade. In: LOURO, Guacira Lopes. O corpo educado: pedagogias da sexualidade. Belo Horizonte: Autêntica, 2007, p. 35-82. 


\section{RESUMO}

Este trabalho é fruto de uma pesquisa preocupada com a formação docente para as discussões sobre diversidade de gênero e sexual na escola, desenvolvida com três grupos do PIBID de uma Universidade pública federal de Minas Gerais. Partimos da importância desse programa para a formação e para o trabalho com as relações de gênero e sexualidade, vamos trabalhar com o PIBID na educação infantil. Um grupo que envolve licenciandas(os) e professoras(es) da educação básica tendo como pressuposto a desnaturalização e a desestabilização das visões normatizadoras e normalizadoras dos gêneros e das sexualidades. A problematização foi a metodologia de análise adotada a partir da perspectiva foucaultiana e pós estruturalista que nos possibilitou colocar sob suspeita as formas de saber e a constituição dos sujeitos atravessados por discursos e por relações de poder.

Palavras chaves: formação docente, gênero, sexualidade

\section{ABSTRACT}

This work is the result of a research concerned with teacher training for the discussions on gender and sexual diversity at school, developed with three groups of PIBID from a Federal University of Minas Gerais. We start with the importance of this program for the training and work with the relations of gender and sexuality, we will work with the PIBID in the infantile education. A group that involves licensed and teachers of basic education having as a premise the denaturalization and destabilization of normative and normalizing visions of the genres and sexualities. The problematization was the methodology of analysis adopted from the foucaultian and post-structuralist perspective that enabled us to put under suspicion the forms of knowledge and the constitution of subjects crossed by discourses and by relations of power.

Key words: teacher training, gender, sexuality

\section{RESUMEN}

Este trabajo es fruto de una investigación preocupada por la formación docente para las discusiones sobre diversidad de género y sexual en la escuela, desarrollada con tres grupos del PIBID de una Universidad pública federal de Minas Gerais. Partimos de la importancia de este programa para la formación y para el trabajo con las relaciones de género y sexualidad, vamos a trabajar con el PIBID en la educación infantil. Un grupo que involucra licenciandos y profesoras de la educación básica teniendo como presupuesto la desnaturalización y la desestabilización de las visiones normatizadoras y normalizadoras de los géneros y de las sexualidades. La problematización fue la metodología de análisis adoptada a partir de la perspectiva foucaultiana y post estructuralista que nos posibilitó poner bajo sospechosas las formas de saber y la constitución de los sujetos atravesados por discursos y por relaciones de poder.

Palabras claves: formación docente, género, sexualidad

Submetido em Nov./2016

Aceito em Jul./ 2017

Revista Teias v. 18, n. 50, 2017 (Jul./Set.): Conversas sobre formação de professores, práticas e currículos 